\title{
Relation of nicotine yield of cigarettes to blood nicotine concentrations in smokers
}

\author{
M A H RUSSELL, M JARVIS, R IYER, C FEYERABEND
}

\section{Summary and conclusions}

Blood nicotine and carboxyhaemoglobin (COHb) concentrations were studied in 330 smokers (206 women and 124 men). Blood nicotine concentrations in individual smokers varied from 25 to $444 \mathrm{nmol} / 1$ (4 to $72 \mathrm{ng} / \mathrm{ml})$. The average concentration, $203 \mathrm{nmol} / 1(33 \mathrm{ng} / \mathrm{ml})$, was the same in the men and the women, although cigarette consumption was higher in the men. Despite large differences in nicotine yield, there was no relation between blood nicotine concentration and the type of cigarette smoked: smokers of plain, untipped cigarettes (1.9 mg nicotine), cigarettes with unventilated filters (1.3 $\mathrm{mg}$ nicotine), and cigarettes with ventilated filters ( $0.8 \mathrm{mg}$ nicotine) had similar blood nicotine concentrations. Cigarette consumption was also similar in these three groups. The correlation between blood nicotine concentration and nicotine yield of cigarette, though significant, was low $(0.21, p<0.001)$, showing that the nicotine yield of the cigarettes accounted for only $4.4 \%$ of the variation in blood nicotine concentrations. Similarly, the low correlation of 0.30 between $\mathrm{COHb}$ concentration and cigarette consumption suggests that cigarette consumption accounted for only $9 \%$ of the variation in the amount of smoke taken into the smokers' lungs.

These results suggest that the assumed health advantage of switching to lower-tar and lower-nicotine cigarettes may be largely offset by the tendency of smokers to compensate by increasing inhalation. The findings of epidemiological studies showing lower risks with filtertipped cigarettes may be attributable to other factors such as biases in the samples and changes in the quality and carcinogenicity of tobacco tar, rather than to reduced tar intake.

\section{Introduction}

The hazards of cigarette smoking are widely believed to be reduced by lowering the tar and nicotine yields of cigarettes. ${ }^{1-4}$ Many countries now publish official tables listing the yields, and various approaches have been considered to discourage the manufacture and use of high-tar brands. In Britain, for example, a supplementary tax was introduced in 1978 on cigarettes in the "high tar" category (29 $\mathrm{mg}$ and over).

This official "low-tar, low-nicotine" approach to safer cigarettes is based on two related assumptions: (i) that the amount of smoke taken in by smokers is largely determined by the standardised machine-smoked yields of the cigarettes; and (ii) that in consequence changing to lower-tar brands will result in roughly proportionate reductions in intake. The smoking

\footnotetext{
$\overline{\text { Addiction Research Unit, Institute of Psychiatry, Maudsley Hospital, }}$ London SE5 6AF

M A H RUSSELL, MRCP, MRCPSYCH, senior lecturer and consultant psychiatrist

M JARVIS, BSC, MPHIL, clinical psychologist

$R$ IYER, statistical assistant

Poisons Unit, New Cross Hospital, London SE14

C FEYERABEND, BSC, biochemist
}

patterns of people, however, do not mirror those of the smoking machine. Individuals vary widely in how they puff and inhale, and, more importantly, unlike the machine, when switching brands they tend to modify their smoking pattern to maintain their intake of smoke at a fairly constant level. ${ }^{5-12}$ It is important, therefore, to know to what extent the benefit of switching to lower-tar cigarettes is offset by the tendency of smokers to compensate by smoking more cigarettes or increasing inhalation.

Since 1974 we have been measuring blood nicotine and carboxyhaemoglobin ( $\mathrm{COHb}$ ) concentrations in smokers attending our smokers' clinic and in volunteers taking part in various experimental studies on smoking behaviour. This has provided data that have enabled us to examine the relation of the blood nicotine concentrations in smokers to the type of cigarettes they smoke.

\section{Subjects and methods}

Data on smoking habits and blood nicotine and $\mathrm{COHb}$ concentrations were available from 212 women and 151 men who attended the Maudsley Hospital smokers' clinic or volunteered for experimental studies on smoking at the addiction research unit. We excluded those who smoked cigars or hand-rolled cigarettes, leaving 206 women and 124 men who regularly smoked manufactured cigarettes for which tar and nicotine yields were available from the official tables published by the Department of Health. Carbon monoxide (CO) yields, though measured by the Government Chemist, were withheld by the Department of Health. The Tobacco Advisory Council, however, provided data on $\mathrm{CO}$ yields of some brands.

All subjects attended in the afternoon and had been instructed to smoke their usual brand in their usual way. On arrival they were asked to smoke one of their usual cigarettes, and a venous blood sample was taken two minutes after they had finished it. The samples were analysed for $\mathrm{COHb}$ by using an IL $182 \mathrm{CO}$-oximeter, ${ }^{13}$ and plasma nicotine concentration was measured by gas chromatography. ${ }^{14}$

\section{Results}

Table I gives details of the cigarette consumption, type of cigarette smoked, and blood nicotine and $\mathrm{COHb}$ concentrations in the men and women. Cigarette consumption on day refers to the number of cigarettes smoked on the day of attendance up to the time of blood sampling. The standard deviations were similar in men and women. The lower mean $\mathrm{COHb}$ concentration in the men was partly due to the higher proportion who smoked plain cigarettes; the difference between men and women was not significant when the smokers of

TABLE I-Cigarette consumption, type of cigarette smoked, and blood nicotine and $\mathrm{COHb}$ concentrations in men and women

\begin{tabular}{|c|c|c|c|}
\hline & $\begin{array}{c}\text { Men } \\
(n=124)\end{array}$ & $\begin{array}{r}\text { Women } \\
(\mathrm{n}=206)\end{array}$ & $\begin{array}{l}\text { Significance } \\
\text { of difference }\end{array}$ \\
\hline Smoking plain cigarettes & $13 \cdot 7$ & 1.9 & $\chi^{2}=18.0 ; p<0.001$ \\
\hline $\begin{array}{l}\text { o Smoking low-nicotine } \\
\text { cigarettes }(<1.0 \mathrm{mg})\end{array}$ & $25 \cdot 0$ & $27 \cdot 2$ & $\chi^{2}=0.2 ; \mathrm{NS}$ \\
\hline $\begin{array}{l}\text { consumption per day } \\
\text { Average cigarette }\end{array}$ & $36 \cdot 2$ & $32 \cdot 6$ & $t=2.3 ; \mathrm{p}<0.05$ \\
\hline $\begin{array}{l}\text { consumption on day } \\
\text { Average tar yield of }\end{array}$ & $20 \cdot 7$ & $18 \cdot 2$ & $t=2.0 ; \mathrm{p}<0.05$ \\
\hline cigarettes (mg/cigarette) & $17 \cdot 3$ & $15 \cdot 8$ & $t=2.8 ; \mathrm{p}<0.01$ \\
\hline $\begin{array}{l}\text { Average nicotine yield of } \\
\text { cigarettes (mg/cigarette) } \\
\text { Average blood nicotine }\end{array}$ & $1 \cdot 3$ & $1 \cdot 2$ & $t=2.5 ; \mathrm{p}<0.02$ \\
\hline $\begin{array}{l}\text { (nmol/1) } \\
\text { Average COHb }\left({ }_{0}^{\circ}\right)\end{array}$ & $\begin{array}{c}205 \\
7 \cdot 8\end{array}$ & $\begin{array}{c}200 \\
8 \cdot 6\end{array}$ & $\begin{aligned} t & =0.5 ; \mathrm{NS} \\
t & =2 \cdot 7 ; \mathrm{p}<0.01\end{aligned}$ \\
\hline
\end{tabular}

Conversion: SI to traditional units-Blood nicotine: $1 \mathrm{nmol} / 1 \approx 0 \cdot 16 \mathrm{ng} / \mathrm{ml}$. 
plain cigarettes were excluded $(8.0 v 8.6 \%$ respectively; $t=1.9)$. Similarly, the average tar and nicotine yields of the cigarettes smoked were not significantly different between men and women when smokers of plain cigarettes were excluded: tar yields averaged 15.9 and $15.6 \mathrm{mg} /$ cigarette for men and women respectively, and nicotine yields 1.18 and $1.16 \mathrm{mg} /$ cigarette respectively.

Table II shows the relation between cigarette consumption, tar and nicotine yields, and blood nicotine and $\mathrm{COHb}$ concentrations.

RELATION OF NICOTINE YIELD OF CIGARETTES TO BLOOD NICOTINE CONCENTRATION

Figure 1 shows the blood nicotine concentration in each subject according to the type of cigarette smoked and its nicotine yield. The plain cigarettes, with nicotine yields of $1.7 \mathrm{mg}$ or more, were all in the "middle to high tar" group (23-28 mg tar/cigarette) or "high tar" group ( $29 \mathrm{mg}$ or more/cigarette) in the Government tables. Cigarettes with unventilated filters yielding $1 \cdot 2-1 \cdot 7 \mathrm{mg}$ nicotine were mostly in the "middle tar" group (17-22 mg/cigarette), though some were in the "low to middle tar" group (11-16 mg/cigarette). Most of the cigarettes with nicotine yields of $0.9 \mathrm{mg}$ or less were from the "low tar" group ( $\leqslant 10 \mathrm{mg} /$ cigarette). None of our subjects smoked the four brands available on the British market with nicotine yields below $0.6 \mathrm{mg} /$ cigarette.

Blood nicotine concentrations varied widely and bore little relation to the nicotine yields of the cigarettes, although there was a small positive relation between the two variables $(r=0.26$ in the women $(p<0.001) ; r=0.17$ in the men $(p<0.03))$. Concentrations were similar in the men and the women (fig 1, table I), despite the higher daily cigarette consumption of the men.

Of the variables measured, the nicotine yield of the cigarette was the main determinant of blood nicotine concentration, but its contribution was small. Cigarette consumption contributed even less. Table III shows that the nicotine yield of cigarettes together with cigarette consumption accounted for only $6.5 \%$ of the variance in blood nicotine concentrations. Consumption on the day of study was a better predictor than average daily consumption. The positive correlation of tar yield with blood nicotine concentration was largely due to the correlation between $\operatorname{tar}$ and nicotine yields, but the negative beta coefficient shows that tar yield had an independent negative relation to blood nicotine concentration.

RELATION OF BLOOD NICOTINE AND COHb CONCENTRATIONS TO TYPE OF CIGARETTE

Table IV shows the blood nicotine and $\mathrm{COHb}$ concentrations in smokers of plain cigarettes, cigarettes with unventilated filter tips, and cigarettes with ventilated filter tips. Despite large differences in the machine-smoked yields of the different types of cigarette the blood concentrations in the smokers were not significantly different. This comparison, however, is marred by the overlap in the nicotine yields of these three types of cigarette (fig 1); it also takes no account of the size of the cigarettes (king size, standard, and small).

To gain some idea of how the nicotine and $\mathrm{CO}$ intake of the smoking

TABLE II-Correlations between cigarette consumption, tar and nicotine yields of cigarettes, and blood nicotine and COHb concentrations in all subjects (men below diagonal, women above diagonal)

\begin{tabular}{|c|c|c|c|c|c|c|c|c|c|c|c|c|}
\hline & & & & & & & Consumption/ & $\begin{array}{l}\text { Consumption } \\
\text { on day }\end{array}$ & $\underset{\text { yield }}{\text { Tar }}$ & $\begin{array}{c}\text { Nicotine } \\
\text { yield }\end{array}$ & $\underset{\text { nicotine }}{\text { Blood }}$ & $\mathrm{COHb}$ \\
\hline Consumption/day & . & . & . & . & . & . & 一 & $\begin{array}{c}0.72 \\
(p=0.001)\end{array}$ & -0.02 & -0.05 & $0 \cdot 10$ & $\begin{array}{c}0.22 \\
(p=0.001)\end{array}$ \\
\hline Consumption on day & . & . & . & . & . & . & $\begin{array}{c}0.73 \\
(p=0.001)\end{array}$ & 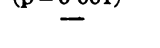 & -0.02 & -0.01 & $\begin{array}{c}0.19 \\
(\mathrm{p}=0.004)\end{array}$ & $\begin{array}{c}0.30 \\
(p=0.001)\end{array}$ \\
\hline Tar yield of cigarette & . & . & . & . & . & . & 0.04 & -0.08 & - & $\begin{array}{c}0.87 \\
(p=0.001)\end{array}$ & $\begin{array}{c}0.14 \\
(\mathrm{p}=0.03)\end{array}$ & 0.08 \\
\hline Nicotine yield of cigarette & . & . & . & . & .. & . & 0.02 & $-0 \cdot 15$ & $\begin{array}{c}0.88 \\
(\mathrm{p}=0.001)\end{array}$ & & $(p=0.001)$ & 0.05 \\
\hline Blood nicotine concentration & & . & . & . & . & . & 0.09 & 0.04 & $\begin{array}{l}(p=0.16 \\
(p=0.05)\end{array}$ & $\begin{array}{c}0.17 \\
(p=0.03)\end{array}$ & & $\begin{array}{c}0.53 \\
(p=0.001)\end{array}$ \\
\hline $\mathrm{COHb}$ concentration & . & . & . & .. & . & . & $\begin{array}{c}0.17 \\
(p=0.03)\end{array}$ & $\begin{aligned} & 0.27 \\
&(p=0.002)\end{aligned}$ & $\begin{array}{c}(p=0.16 \\
(p=0.05)\end{array}$ & $\begin{array}{c}-0.21 \\
(p=0.01)\end{array}$ & $\begin{array}{c}0.51 \\
(p=0.001)\end{array}$ & $(p=0.001)$ \\
\hline
\end{tabular}
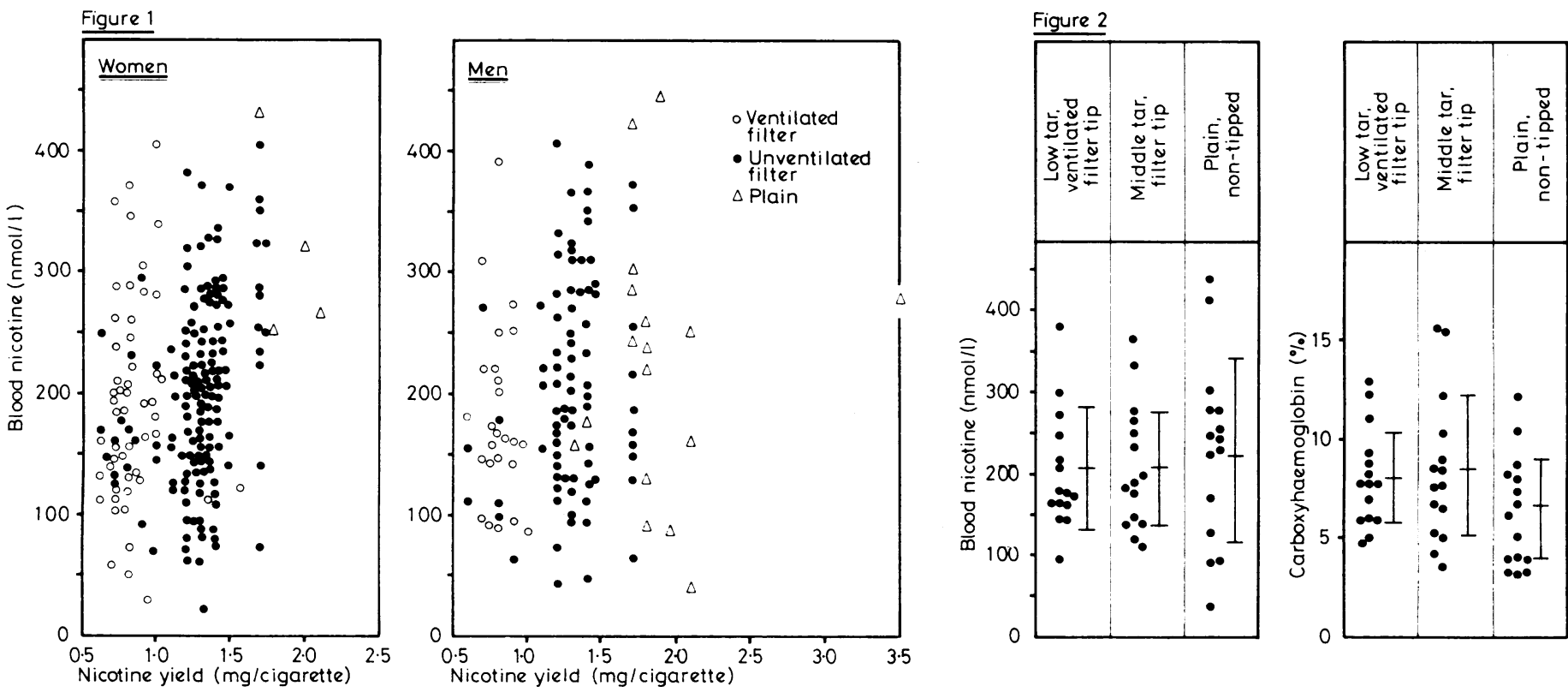

FIG 1-Blood nicotine concentrations in men and women according to type of cigarette smoked.

Conversion: SI to traditional units-Blood nicotine: $1 \mathrm{nmol} / 1 \approx 0 \cdot 16 \mathrm{ng} / \mathrm{ml}$.

FIG 2-Blood nicotine and COHb concentrations in men smoking plain, non-tipped cigarettes; middle-tar, medium-nicotine cigarettes with unventilated filters; and low-tar, low-nicotine cigarettes with ventilated filters ( $\mathrm{n}=15$ in each group, matched for consumption and size of cigarettes). Lines indicate mean $\pm S D$ concentrations.

Conversion: SI to traditional units-Blood nicotine: $1 \mathrm{nmol} / 1 \approx 0 \cdot 16 \mathrm{ng} / \mathrm{ml}$. 
population may have changed over the past 20 years we compared the three main types of cigarettes. (1) Plain (non-filter) cigarettes (tar yield $\geqslant 24 \mathrm{mg}$, nicotine $\geqslant 1.7 \mathrm{mg}$ ), which were the closest approximation available to the high-tar, high-nicotine plain cigarettes of the 1960s. (2) Typical middle-tar, medium-nicotine cigarettes with unventilated filters (tar 17-20 mg, nicotine $1 \cdot 2-1.4 \mathrm{mg}$ ), which were the popular cigarettes of the 1970s. (3) Typical low-tar, low-nicotine cigarettes with ventilated filters (tar $8-11 \mathrm{mg}$, nicotine $0.6-0.9 \mathrm{mg}$ ), which were promoted by health authorities as the safest cigarette of the late 1970 s but were used regularly by only $12 \%$ of the smoking population (National Opinion Poll Survey, January 1979). Since only four of the 206 women smoked plain cigarettes, we confined this comparison to men: 15 men who smoked plain cigarettes were compared with 15 who smoked cigarettes with unventilated and 15 who smoked cigarettes with ventilated filters. The length of the cigarettes (small or standard size; none of the plain cigarettes were king size) was matched in the three groups, as was cigarette consumption. The average number of cigarettes smoked on the day of study in each group was 21.9 (ventilated filter), 24.9 (unventilated filter), and 19.5 (plain); while the average daily consumption was 41.2 (ventilated filter), 41.9 (unventilated filter), and 43.7 (plain). Figure 2 shows the blood nicotine and $\mathrm{COHb}$ concentrations in these three groups.

The mean blood nicotine concentrations were 203, 209, and 231 $\mathrm{nmol} / 1(32.9,33.9$, and $37.4 \mathrm{ng} / \mathrm{ml})$ in the men smoking ventilated filter, unventilated filter, and plain cigarettes respectively; these values were not significantly different $(F=0.6, \mathrm{df}=2 / 28$-analysis of variance for matched groups ${ }^{15}$ ), despite the large differences in nicotine yields $(0.81,1.30$, and $1.96 \mathrm{mg}$ respectively). Mean $\mathrm{COHb}$ concentrations were significantly different between the three groups, being $8 \cdot 0,8 \cdot 2$, and $6 \cdot 2 \%$ in men smoking ventilated filter, unventilated filter, and plain cigarettes respectively $(\mathrm{F}=6.8, \mathrm{df}=2 / 28, \mathrm{p}<0.01-$ analysis of variance for matched groups ${ }^{15}$ ). Average tar yields were $9 \cdot 3,18.3$, and $26.4 \mathrm{mg}$ respectively, and average CO yields $11 \cdot 7,17 \cdot 8$, and $14.8 \mathrm{mg}$ respectively.

Finally, we compared these same three types of cigarettes without controlling for consumption and cigarette size; table $\mathrm{V}$ shows the results. Despite large difierences in tar and nicotine yields (and probably also in $\mathrm{CO}$ yields), blood nicotine and $\mathrm{COHb}$ concentrations were not significantly lower in the smokers of low-nicotine cigarettes with ventilated filters.

\section{Discussion}

Two things should be borne in mind when considering the results of this study. Firstly, the sample did not represent normal smokers in the population, but consisted of heavy smokers whose average daily consumption was double that of the general population. ${ }^{16}$ The proportion who usually smoked a low-nicotine brand ( $<1.0 \mathrm{mg}$ ) was also about double the $12 \%$ found in the general population. The sample thus consisted of exceptionally heavy smokers, most of whom were seeking treatment to help them give up smoking and whose high rate of use of low-nicotine cigarettes was probably an indication of their greater concern for the health risks of smoking. Secondly, their brand of cigarette was self-selected in the sense that it was not forced on them as part of an experiment. In addition, most of those using a lownicotine brand had been doing so for at least a year.

TABLE III-Stepwise multiple regression for cigarette consumption and tar and nicotine yields of cigarettes with blood nicotine concentration as dependent variable

\begin{tabular}{lccccc}
\hline \multicolumn{1}{c}{ Independent variables } & Simple $\mathbf{R}$ & $\begin{array}{c}\text { Stepwise } \\
\text { multiple } \mathbf{R}\end{array}$ & $\mathbf{R}^{2}$ & $\begin{array}{c}\text { Beta } \\
\text { coefficient }\end{array}$ & Significance \\
\hline Nicotine yield of cigarette & 0.211 & 0.211 & 0.044 & 0.415 & $\mathbf{p}<0.001$ \\
Cigarette consumption on day & 0.131 & 0.254 & 0.065 & 0.146 & $\mathbf{p}<0.01$ \\
Tar yield of cigarette & 0.134 & 0.276 & 0.076 & -0.225 & $\mathbf{p}<0.05$ \\
Cigarette consumption per day & 0.104 & & & & NS \\
\hline
\end{tabular}

Since there was no significant difference between the regression for men and women the data shown are for the two sexes combined. $\mathbf{R}^{2}=$ Proportion of variance in blood nicotine concentration accounted for by all the independent variables entered up to and including a given variable. ${ }^{28}$

TABLE IV-Mean cigarette consumption and blood nicotine and COHb concentrations in men and women according to type of cigarette smoked

\begin{tabular}{|c|c|c|c|c|c|c|c|}
\hline & \multicolumn{4}{|c|}{ Men } & \multicolumn{3}{|c|}{ Women* } \\
\hline & $\begin{array}{c}\text { Plain } \\
(\mathrm{n}=17)\end{array}$ & $\begin{array}{l}\text { Unventilated } \\
\text { filter } \\
(n=82)\end{array}$ & $\begin{array}{l}\text { Ventilated } \\
\text { filter } \\
(n=25)\end{array}$ & $\begin{array}{r}\text { Significance } \\
\text { of differences }\end{array}$ & $\begin{array}{l}\text { Unventilated } \\
\text { filter } \\
(\mathbf{n}=150)\end{array}$ & $\begin{array}{c}\text { Ventilated } \\
\text { filter } \\
(n=52)\end{array}$ & $\begin{array}{l}\text { Significance } \\
\text { of differences }\end{array}$ \\
\hline & \multicolumn{7}{|c|}{ Cigarette variables } \\
\hline \multirow[t]{2}{*}{$\begin{array}{l}\text { Tar yield (mg/cigarette) } \\
\text { Nicotine yield (mg/cigarette) }\end{array}$} & $\begin{array}{r}25.9 \\
1.9\end{array}$ & $\begin{array}{r}17 \cdot 9 \\
1 \cdot 3\end{array}$ & $\begin{array}{l}9 \cdot 3 \\
0.8\end{array}$ & $\begin{array}{l}F=400 ; p<0.001 \\
F=88.4 ; p<0.001\end{array}$ & $\begin{array}{r}17 \cdot 7 \\
1 \cdot 3\end{array}$ & $\begin{array}{l}9 \cdot 7 \\
0 \cdot 8\end{array}$ & $\begin{array}{l}t=22.3 ; \mathrm{p}<0.001 \\
t=13.7 ; \mathrm{p}<0.001\end{array}$ \\
\hline & \multicolumn{7}{|c|}{ Smoker variables } \\
\hline $\begin{array}{l}\text { Consumption per day } \\
\text { Consumption on day } \\
\text { Blood nicotine (nmol/l) } \\
\text { COHb (\%) }\end{array}$ & $\begin{array}{c}40 \cdot 3 \\
18 \cdot 8 \\
223 \\
6 \cdot 3\end{array}$ & $\begin{array}{c}34 \cdot 6 \\
20 \cdot 8 \\
208 \\
8 \cdot 0\end{array}$ & $\begin{array}{c}38 \cdot 3 \\
21 \cdot 4 \\
182 \\
7 \cdot 8\end{array}$ & $\begin{array}{l}F=1 \cdot 1 ; N S \\
F=0.4 ; N S \\
F=1 \cdot 0 ; N S \\
F=2 \cdot 7 ; N S\end{array}$ & $\begin{array}{r}32 \cdot 7 \\
17 \cdot 8 \\
32 \cdot 6 \\
8 \cdot 8\end{array}$ & $\begin{array}{r}32 \cdot 2 \\
18 \cdot 6 \\
30 \cdot 9 \\
8 \cdot 0\end{array}$ & $\begin{array}{l}t=0.2 ; \mathrm{NS} \\
t=0.5 ; \mathrm{NS} \\
t=0.8 ; \mathrm{NS} \\
t=1.8 ; \mathrm{NS}\end{array}$ \\
\hline
\end{tabular}

Only cigarette consumption differed significantly between the sexes, being lower in women.

* As only four women smoked plain cigarettes they are not included.

Conversion: SI to traditional units-Blood nicotine: $1 \mathrm{nmol} / 1 \approx 0 \cdot 16 \mathrm{ng} / \mathrm{ml}$

TABLE V-Comparison of average cigarette consumption and blood nicotine and COHb concentrations in smokers of typical low-tar, low-nicotine cigarettes with ventilated filters (tar 8-12 mg; nicotine 0.6-0.9 mg); middle-tar, medium-nicotine cigarettes with unventilated filters (tar 17-20 mg, nicotine 1.2-1.4 mg); and plain cigarettes (tar $>23 \mathrm{mg}$, nicotine $>1.6 \mathrm{mg}$ )

\begin{tabular}{|c|c|c|c|c|c|c|c|}
\hline & \multicolumn{4}{|c|}{ Men } & \multicolumn{3}{|c|}{ Women } \\
\hline & $\underset{(n=15)}{\text { Plain }}$ & $\begin{array}{l}\text { Medium- } \\
\text { Nicotine } \\
(n=55)\end{array}$ & $\begin{array}{c}\text { Low- } \\
\text { Nicotine } \\
(\mathrm{n}=23)\end{array}$ & $\begin{array}{c}\text { Significance } \\
\text { of } \\
\text { difference }\end{array}$ & $\begin{array}{c}\text { Medium- } \\
\text { nicotine } \\
(\mathbf{n}=91)\end{array}$ & $\begin{array}{c}\text { Low- } \\
\text { nicotine } \\
(\mathrm{n}=38)\end{array}$ & $\begin{array}{c}\text { Significance } \\
\text { of } \\
\text { difference }\end{array}$ \\
\hline $\begin{array}{l}\text { Consumption per day } \\
\text { Consumption on day } \\
\text { Blood nicotine (nmol/1) } \\
\text { COHb (\%) }\end{array}$ & $\begin{array}{r}43 \cdot 7 \\
19 \cdot 5 \\
231 \\
6 \cdot 2\end{array}$ & $\begin{array}{c}36 \cdot 2 \\
21 \cdot 6 \\
216 \\
8 \cdot 0\end{array}$ & $\begin{array}{c}39 \cdot 7 \\
22 \cdot 6 \\
188 \\
8 \cdot 0\end{array}$ & $\begin{array}{l}F=1.6 ; \mathrm{NS} \\
F=0.4 ; \mathrm{NS} \\
F=0.9 ; \mathrm{NS} \\
F=2.4 ; \mathrm{NS}\end{array}$ & $\begin{array}{c}32 \cdot 1 \\
16 \cdot 5 \\
199 \\
8 \cdot 8\end{array}$ & $\begin{array}{c}32 \cdot 9 \\
18 \cdot 3 \\
184 \\
8 \cdot 0\end{array}$ & $\begin{array}{l}t=0.3 ; \text { NS } \\
t=1.2 ; \mathrm{NS} \\
t=1.0 ; \mathrm{NS} \\
t=1.6 ; \mathrm{NS}\end{array}$ \\
\hline
\end{tabular}

Conversion: SI to traditional units-Blood nicotine: $1 \mathrm{nmol} / \mathrm{l} \approx 0 \cdot 16 \mathrm{ng} / \mathrm{ml}$. 


\section{COMPARISON OF MEN AND WOMEN}

It is well known that plain cigarettes are used mainly by men and that daily cigarette consumption is higher in men than women. ${ }^{18}$ Our study confirmed this. We are not aware, however, of previous studies comparing blood nicotine and $\mathrm{COHb}$ concentrations in men and women smokers. The blood nicotine concentrations were strikingly similar and averaged $203 \mathrm{nmol} / 1$ (33 $\mathrm{ng} / \mathrm{ml}$ ) in both men and women despite the higher consumption of the men. When the smokers of plain cigarettes were excluded there were no significant differences in $\mathrm{COHb}$ concentrations between the men and women, nor in the average tar and nicotine yields of the cigarettes smoked. Clearly then, among these heavy smokers the inhaling habits of men and women were similar. The higher consumption by men might be due to their greater body weight or possibly to an economic factor, but it is not known why men are more inclined to use plain cigarettes.

RELATION OF INTAKE BY SMOKER TO YIELD AND NUMBER OF CIGARETTES SMOKED

Peak blood nicotine concentrations in individual smokers varied widely-from 25 to $444 \mathrm{nmol} / 1$ ( 4 to $72 \mathrm{ng} / \mathrm{ml}$ ) around the mean of $203 \mathrm{nmol} / 1(33 \mathrm{ng} / \mathrm{ml})$-but bore little relation to the number of cigarettes smoked, the type of cigarette, or its tar and nicotine yield. Many smokers achieved high blood nicotine concentrations from low-nicotine cigarettes, and many smokers of high-nicotine cigarettes had low blood nicotine concentrations. Despite the large differences in nicotine yields, average blood nicotine concentrations were similar in smokers of plain cigarettes (mean yield $1.9 \mathrm{mg}$ nicotine/cigarette), cigarettes with unventilated filters (mean nicotine yield $1.3 \mathrm{mg}$ ), and cigarettes with ventilated filters (mean nicotine yield $0.8 \mathrm{mg}$ ). The correlation between blood nicotine concentration and nicotine yield of cigarette, though significant, was low $(0.21$ for men and women combined, $\mathrm{p}<0.001)$, showing that the nicotine yield of the cigarettes accounted for only $4.4 \%$ of the variation in blood nicotine concentrations.

The longer half life of $\mathrm{COHb}$ (two to three hours) ${ }^{517}$ makes it a better marker of overall smoke intake over the course of a day. Peak blood nicotine concentration is determined more by the intake from the preceding cigarette. ${ }^{18}$ This difference is reflected in the correlations with cigarette consumption, which, though low, were higher for $\mathrm{COHb}$ than for blood nicotine. Even with $\mathrm{COHb}$ the correlation with cigarette consumption was only 0.3 and indicates that the number of cigarettes smoked accounted for only $9 \%$ of the variation in the amount of smoke taken into the lungs.

If the Department of Health had allowed us access to their data on $\mathrm{CO}$ yields of cigarettes we could have related these more systematically to the $\mathrm{COHb}$ concentration. Nevertheless, our findings are similar to those of Wald et al ${ }^{19}$ in showing a tendency for $\mathrm{COHb}$ concentrations to be slightly lower in smokers of plain cigarettes (mean $6.3 \%$ ) than in smokers of filter-tipped cigarettes $(8.0 \%$ and $7.8 \%$ for unventilated and ventilated filters respectively). This is partly due to the slightly lower CO yields of plain cigarettes but more particularly because plain cigarettes are inhaled less deeply. ${ }^{20}$ The similar $\mathrm{COHb}$ concentrations in smokers of cigarettes with ventilated and unventilated filters despite the lower $\mathrm{CO}$ yields of the former (12 $\mathrm{mg} v 19 \mathrm{mg}$ CO per cigarette ${ }^{19}$ ) indicates that the smokers of cigarettes with ventilated filters inhaled more deeply.

\section{IMPLICATIONS FOR LESS HAZARDOUS CIGARETTES}

This study showed that cigarette consumption, tar and nicotine yield of cigarettes, and the type of cigarette made little difference and accounted for little of the variance in blood nicotine and $\mathrm{COHb}$ concentrations. This suggests that the smoke intake of smokers is largely determined by their individual pattern of puffing and inhaling and that the assumed health advantage of smoking cigarettes with lower machine-smoked tar and nicotine yields is mostly offset by the tendency of smokers to modify their smoking pattern to regulate their intake to a fairly constant level. Moreover, the small tendency for smokers of lower-nicotine cigarettes to have lower blood nicotine concentrations might partly have occurred because the subjects selected their own brand of cigarettes. For instance, the smokers who had chosen lower-nicotine brands might possibly have tended to be those with slightly lower blood nicotine concentrations before they changed brands; and this factor, rather than any reduction in intake after changing, might have contributed to the low correlations observed between blood nicotine concentration and nicotine yield of cigarette. Owing to the high correlation of tar and nicotine yields we cannot say from this study whether the self-regulation of smoke intake is mediated by a desire for a constant intake of nicotine or tar or by some other factor. Whatever its cause, our results suggest that switching to cigarettes with lower tar and nicotine yields may not reduce tar and nicotine intake at all, or at most by a disappointingly small degree.

Epidemiological studies have shown that the incidence of lung cancer and changes in the bronchial epithelium are reduced in smokers who have smoked filter-tipped rather than plain cigarettes. ${ }^{21-25}$ It has been widely assumed that this is due to a reduced tar intake. Our data, however, suggest that nicotine and hence tar intake is unlikely to be appreciably reduced by a switch from plain to filter-tipped cigarettes. How then can our data be reconciled to the epidemiologicai data?

Firstly, the epidemiological data are based on self-selected samples-that is, smokers who had switched to filter-tipped cigarettes were compared with those who for their own reasons had not switched. Besides the many social factors, the smokers who switched may quite possibly have been those who inhaled less. Switching per se cannot, therefore, be assumed to reduce the incidence of lung cancer. Secondly, the gradual decline in lung cancer, even among smokers, is not necessarily due to the concurrent switching of the smoking population to filter-tipped cigarettes with lower tar and nicotine yields. Over the same period changes in the processing of tobacco have reduced its specific carcinogenicity. ${ }^{26}$ The reasons are unfortunately unknown. Thus a given amount of tobacco tar from the cigarettes of the 1970s was less likely to produce cancer than the same amount of tar from cigarettes of the 1950s.

Thus the risks of developing cancer from smoking seem to have been reduced, although the tar and nicotine intakes by smokers have remained largely unchanged, and the lower risk seems to be due more to changes in the quality and carcinogenicity of tobacco tar rather than to a reduced tar intake. Tar and nicotine intake are not appreciably reduced by switching to low-tar, low-nicotine cigarettes, owing to the tendency of smokers to smoke these cigarettes more intensively and inhale them more deeply. We have suggested before that tar intake is more likely to be reduced by developing low-tar, mediumnicotine cigarettes. ${ }^{5} 27$ The findings of this study strengthen the case for a new approach in this direction.

We thank Dr P V Cole and Mr Y Saloojee for measuring the COHb concentrations; the Tobacco Advisory Council for providing data on CO yields of some brands; and Mrs Jean Crutch for secretarial help. Our colleagues Dr J R Eiser, Mr M Raw, and Mr C Taylor gave useful advice during the analysis and write-up. Financial support was provided by the Medical Research Council.

\section{References}

1 Wynder EL, Hoffman D. Tobacco and health: a societal challenge. $N$ Engl f Med 1979;300:894-903.

2 Gori GB, Lynch CJ. Towards less hazardous cigarettes. $F A M A$ 1978; 240:1255-9.

3 World Health Organisation. Controlling the smoking epidemic. WHO Tech Rep Ser 1979;636. 
4 US Surgeon General. Report. Smoking and health. Washington, DC: US Government Printing Office, 1979.

${ }^{5}$ Russell MAH, Wilson C, Patel UA, Cole PV, Feyerabend C. Comparison of the effect on tobacco consumption and carbon monoxide absorption of changing to high and low nicotine cigarettes. $\mathrm{Br} M e d \mathcal{F} 1973$;iv:512-6.

- Russell MAH, Wilson C, Patel UA, Cole PV, Feyerabend C. Plasma nicotine levels after smoking cigarettes with high, medium, and low nicotine yields. $\mathrm{Br} \mathrm{Med} \mathcal{F} 1975$;ii:414-6.

${ }^{7}$ Russell MAH. Self-regulation of nicotine intake by smokers. In: Battig, $\mathrm{K}$, ed. Behavioral effects of nicotine. Basle: Karger, 1978:108-22.

${ }^{8}$ Sutton SR, Feyerabend C, Cole PV, Russell MAH. Adjustment of smokers to dilution of tobacco smoke by ventilated cigarette holders. Clin Pharmacol Ther 1978;24:395-405.

- Schachter S. Nicotine regulation in heavy and light smokers. $\mathcal{F}$ Exp Psychol [Gen] 1977;106:5-12.

10 Ashton H, Stepney R, Thompson JW. Self-titration by cigarette smokers. Br Med F 1979;ii:357-60.

${ }^{11}$ Creighton DE, Lewis PH. The effect of different cigarettes on human smoking patterns. In: Thornton RE, ed. Smoking behaviour: physiological and psychological influences. London: Churchill Livingstone, 1978: 289-300.

12 Thornton RE, ed. Smoking behaviour: physiological and psychological influences. London: Churchill Livingstone, 1978.

13 Russell MAH, Cole PV, Brown E. Absorption by non-smokers of carbon monoxide from room-air polluted by tobacco smoke. Lancet 1973;i: 576-9.

14 Feyerabend C, Russell MAH. Improved gas-chromatographic method and micro-extraction technique for the measurement of nicotine in biological fluids. F Pharm Pharmacol 1979;31:73-6.

15 Winer BJ. Statistical principles in experimental design. New York: McGrawHill, 1962:298.

16 Lee PN, ed. Statistics of smoking in the United Kingdom. Research paper 1. 7th ed and supplements. London: Tobacco Research Council, 1976.
17 Wald N, Howard S, Smith PG, Bailey A. Use of carboxyhaemoglobin levels to predict the development of diseases associated with cigarette smoking. Thorax 1975;30:133-40.

18 Russell MAH, Feyerabend C. Cigarette smoking: a dependence on highnicotine boli. Drug Metab Rev 1978;8:29-57.

19 Wald N, Idle M, Smith PG. Carboxyhaemoglobin levels in smokers of filter and plain cigarettes. Lancet 1977;i:110-2.

${ }^{20}$ Rawbone RG, Murphy K, Tate ME, Kane SJ. The analysis of smoking parameters, inhalation and absorption of tobacco smoke in studies of human smoking behaviour. In: Thornton RE, ed. Smoking behaviour: physiological and psychological influences. London: Churchill Livingstone, 1978:171-94.

${ }^{21}$ Bross IDJ, Gibson R. Risks of lung cancer in smokers who switch to filter cigarettes. Amer $\mathcal{F}$ Public Health 1968;58:1396-403.

22 Wynder EL, Mabuchi K, Beattie EJ. The epidemiology of lung cancer: recent trends. F $A M A$ 1970;213:2221-8.

${ }^{23}$ Hammond EC, Garfinkel L, Seidman H, Lew EA. Tar and nicotine content of cigarette smoke in relation to death rates. Environ Res 1976; 12:263-74.

${ }^{24}$ Dean G, Lee PN, Todd GF, Wicken AJ. Report on a second retrospective mortality study in north east England. Part 1. Research paper 14. London: Tobacco Research Council, 1977.

25 Auerbach O, Hammond EC, Garfinkel L. Changes in bronchial epithelium in relation to cigarette smoking, 1955-1960 vs 1970-1977. N Engl f Med $1979 ; 300: 381-6$.

${ }^{26}$ Gori GB. Low-risk cigarettes : a prescription. Science 1976;194:1243-6.

27 Russell MAH. Low-tar, medium-nicotine cigarettes: a new approach to safer smoking. $\mathrm{Br}$ Med $\mathcal{f} 1976 ; \mathrm{i}: 1430-3$.

${ }^{28}$ Draper NR, Smith H. Applied regression analysis. Toronto: Wiley, 1967: 163.

(Accepted 18 fanuary 1980)

\section{Can insulin-treated diabetics be given beta-adrenergic blocking drugs?}

\section{Summary and conclusions}

Lack of awareness of hypoglycaemia leading to loss of consciousness is a serious problem in some insulintreated diabetics, and beta-blocking drugs may increase this hazard. A prospective study was therefore carried out over eight months to determine the incidence of hypoglycaemic episodes in 50 insulin-treated diabetics taking beta-blockers as compared with 100 diabetic controls matched for age, sex, and duration of diabetes. The incidence of loss of consciousness from hypoglycaemia was the same in both groups and was unrelated to the dose of beta-blocking drug used. Five patients taking beta-blockers and 10 controls had episodes of unconsciousness, but four of these patients taking betablockers had had similar episodes in the two years preceding treatment.

It is concluded that beta-blocking drugs are generally safe in insulin-treated diabetics and that hypoglycaemic unconsciousness resulting from their use is rare.

Diabetic Department, King's College Hospital, London SE5 9RS ANTHONY H BARNETT, BSC, MRCP, registrar (present appointment: MRC Research Fellow)

DAVID LESLIE, MRCP, MRC Research Fellow

PETER J WATKINS, MD, FRCP, consultant

\section{Introduction}

Beta-adrenergic blocking agents are an important advance in the management of hypertension and ischaemic heart disease. Concern has been expressed, however, about using these agents in insulin-treated diabetics because they might possibly reduce or eliminate the warning symptoms of hypoglycaemia, which are partly due to adrenergic stimulation. Hypoglycaemic loss of consciousness has been reported in an insulin-dependent diabetic taking beta-blocking drugs, ${ }^{1}$ but the extent of this problem is unknown.

We conducted a prospective investigation to discover the incidence of unconsciousness from hypoglycaemia in insulintreated diabetics receiving beta-blocking drugs compared with matched controls.

\section{Patients and methods}

We studied for eight months 50 insulin-treated diabetics taking beta-adrenergic blocking drugs. Forty-three were taking noncardioselective drugs and seven cardioselective drugs (acebutalol or metoprolol). Thirty-six of the patients were being treated for hypertension, 10 for angina, two for arrhythmias, and two for anxiety. One hundred insulin-treated diabetics who were not taking betablocking drugs served as controls and were selected consecutively to match for age, sex, and duration of diabetes.

The patients were each given a diary card on which to record details of episodes that they considered to be hypoglycaemic. We kept a separate card to record the details of each patient and the nature of each hypoglycaemic episode. Particular attention was paid 